\title{
PROLONGED SURVIVAL IN A PATIENT WITH CHRONIC MYELOID LEUKEMIA
}

SHUKLA A. ${ }^{1}$

KALRA O.P. ${ }^{2}$

\section{SUMMARY:}

Patients with chronic myeloid leukemia treated with intermittent busulphan therapy have an average survival rate of 2 to 4 years. The authors report here a patient who continues to survive beyond one decade on busulphan therapy.

\section{INTRODUCTION:}

Allogeneic bone marrow transplantation from a genotypically HLA-matched sibling is the standard and most effective therapy for chronic myeloid leukemia (CML). However, most of the patients are still managed with chemotherapy. Despite its lower efficacy than hydroxyurea or interferon, busulphan has certain advantages. It has a predictable dose and gradually lowers the blood counts ${ }^{1}$. In patients receiving intermittent busulphan therapy, median survival time is 2 to 4 years ${ }^{2}$. We report here a case, probably the first one from Nepal, who continues to survive for over 10 years after the diagnosis of CML.

\section{CASE HISTORY:}

A 32-year-old female presented in April 1989 with pain in the left upper abdomen, weight loss and fatigue. On examination, there was no lymphadenopathy and the spleen was palpable $5 \mathrm{~cm}$ below the left costal margin. Hematological investigations revealed $\mathrm{Hb}$ of $-12 \mathrm{~g} / \mathrm{dl}$; TLC $-1.8 \times 10^{5}$ $\mathrm{mm}^{3}$; DLC - myeloblasts 2, promyelocytes 21, myelocytes 12 , metamyelocytes 18 , polymorphs 40, lymphocytes 4, monocytes 2 and eosinophil 1. Platelet count was $1.15 \times 10^{5} / \mathrm{mm}^{3}$. Bone marrrow examination revealed a hypercellular marrow with a predominant myeloid hyperplasia. Erythropoiesis was normoblastic and megakaryocytes were unremarkable. A diagnosis of chronic myeloid leukemia in the chronic phase was made. The patient was put on treatment with busulphan and the dose was monitored based on her white blood cell counts. During the first 4 years of her illness, her hematological parameters were stable and she required only 1 to 2 courses of busulphan therapy; subsequently, she was been requiring 3 to 4 courses of busulphan therapy over a years. She often complained of pain in the left upper abdomen due to a massive splenomegaly.

In April 1998, the patient developed severe pain in the left upper abdomen and physical examination showed severe pallor and massive splenomegaly. Hematological investigation revealed $\mathrm{Hb}-$

1. Assitant Professor, Department of Medicine, B.P. Koirala Institute of Health Sciences, Dharan, Nepal.

2. MD, NMAMS, DM, FICP, Professor \& Head, Department of Medicine, B.P. Koirala Institute of Health Sciences, Dharan, Nepal.

Address of Correspodence : Dr. Ashutosh Shukla, Assistant Professor, Department of Medicine

B.P. Koirala Institute of Health Sciences, Dharan, Nepa.

Tel : 977-25-21017 Ext. 3036 (R). 2052 (O)

Fax\#977-25-20251, E-mail : Shuklaashutosh@ @otmail.com 
$4.6 \mathrm{~g} / \mathrm{dl} ;$ TLC $-2.25 \times 10^{5} / \mathrm{mm}^{3}$ and platelets $1.15 \times 10^{5} / \mathrm{mm}^{3}$. Bone marrow examination revealed a mild fibrosis; however, cells of all the series were present. A splenic infarct was suspected and bed rest and analgesics were recommended. The dose of busulphan was increased to $8 \mathrm{mg} /$ day and the patient was given blood transfusions. She was subsequently maintained on intermittent busulphan at $2 \mathrm{mg} /$ day.

\section{DISCUSSION:}

On intermittent busulphan therapy, survival beyond 4 years is rare. One of the authors has already reported a patient who had been on intermittent busulphan therapy and survived for 17 years, after which he developed myeloblastic blast transformation and $\operatorname{died}^{3}$. In the literature, a few more cases of prolonged survival have been reported. Golde et.al. ${ }^{4}$ reported a case of CML who survived for 15 years while receiving 19 courses of busulphan. The duration of remission tends to decline with repeated courses of therapy, but this is not always the case. Unfortunately, the chronic phase usually progresses to the more advanced stage of the disease. This progression to the blast phase occurs at an approximate rate of $5 \%$ in the first year and 20-25\% each year thereafter. Once the blast phase occurs, long-term survival is uncommon, with most patients succumbing within 3 to 6 months.

The main underlying reason for prolonged survival in most patients described in literature has been prolonged remission following busulphaninduced bone marrow hypoplasia. In some cases, profound myelosuppression may also eliminate the $\mathrm{Ph}$ positive chromosome, thus changing the karyotype status of the patients ${ }^{5}$. After the karyotype conversion, the risk of blast transformation becomes negligible. In some patients, the $\mathrm{Ph}$ posi- tive chromosome may not disappear but patients may be maintained in complete hematological remission for a long time with a decreased percentage of $\mathrm{Ph}$ positive cells ${ }^{4}$. These $\mathrm{Ph}$ positive chromosomes lack or lose their characteristic proliferative advantage. The prolonged course of the disease may be due to the relatively stable mosaicism of the $\mathrm{Ph}$ chromosome.

The present case has survived for over a decade; however, she continues to have distressing symptoms due to massive splenomegaly resulting in splenic infarcts despite hematological improvement. In such cases, local splenic irradiation may prove useful.

\section{REFERENCES:}

1. Larson RS, Wolff SN. Chronic myeloid leukemia. In : Richard LG, Foerster J, Lukens J, Paraskevas F, Greer JP, Rodgers GM, eds. Wintrobe's Clinical Hematology, Baltimore: Williams \& Wilkins, 1999 2342-64.

2. Sokal JE. Evaluation of survival data for chronic myelocytic leukemia. A $\mathrm{m} J$ Haematol 1976; 1: 493-500.

3. Kalra OP, Prakash C, Mittal R, Verma SC, Mohanty D. Prolonged survival in chronic granulocytic leukemia. J Assoc Physicians India 1998; 36: 352-3.

4. Golde DW, Barsch NL, Sparkes RS. Chromosomal mosaicism associated with prolonged remission in chronic myelogenous leukemia. Cancer 1976; 37:1849-52.

5. Djaldetti M, Padeh B, Pinkhas J. Prolonged remission in chronic myeloid leukemia after one course of busulphan. Blood 1966; 27: 103-9. 